\title{
Research of Logistics Engineering Training Mode based on School-Enterprise Cooperation
}

\author{
Wen Chen ${ }^{1, a}$, Guanghua $\mathrm{Li}^{2, \mathrm{~b}}$ \\ ${ }^{1}$ Nanchang Institute of Science \& Technology, Nanchang, Jiangxi, 330000 \\ ${ }^{a}$ email, ${ }^{b}$ email
}

Keywords: Logistics Engineering, Training Mode, School-Enterprise Cooperation

\begin{abstract}
School-enterprise training mode is the basic way of vocational education reform and development. Depending on industry, vocational colleges and enterprises to establish how beneficial school-enterprise cooperation mechanisms and adapt teaching mode of this mechanism, is currently the key to a breakthrough and Higher Vocational Education Reform. Currently, colleges and universities in recent years, higher vocational logistics management professional in this field has been fruitful exploration and achieved fruitful results. In practice, however, we can feel the deep operating mechanism of logistics professional school-enterprise cooperation is still not perfect, the status quo is not satisfactory school-enterprise cooperation; frequent logistics business uncertainty and changes in market demand and logistics between the professional education program conflict, as well as "work and study, school-enterprise cooperation," the short-term behavior of the disorder and lead to conflict, it is difficult to form a "combination working with learning, school-enterprise cooperation," the planned long-term mechanism.
\end{abstract}

\section{Introduction}

In the 21st century, open innovation has become the main model of innovation that allows businesses or organizations to meet the market demand for rapid development and increasingly fierce competition. Open innovation is an enterprise or other organization can take the internal and external resources to integrate innovation to create value with innovative partners to share the risk and share profits. Nature is open access and use of external innovation resources, emphasis on organizational innovation effective integration of internal and external resources, enabling organizations across traditional boundaries no longer completely on their own. Therefore, businesses or other organizations must seek a joint with Foreign Minister organizational boundaries associated with continuous innovation and development. Vocational colleges and enterprises in human resources, research and other aspects of the school-enterprise cooperation is undoubtedly a prerequisite for the.

\section{Necessity of Logistics Professionals to Carry out School-Enterprise Cooperation}

Because of the logistics industry is productive service industry, with a strong technical barriers, but also has a direct-to-customer to meet customer demand for personalized features. The traditional strong foundation, the theory of heavy, wide caliber training model still can not meet the needs of logistics enterprises, rich theoretical knowledge and practical skills has become a problem the lack of vocational college, logistics professional teaching prevalent currently. There is a big difference in the quality of vocational schools to train a lot of talent out of the traditional culture methods talent quality and business requirements. Thus, school-enterprise cooperation is the inevitable choice of vocational college, logistics professional survival.

"School-enterprise cooperation" is the basic law of higher vocational education should follow, from the perspective of open innovation, logistics professionals as the application of higher vocational institutions strong professional, must actively introduce industry enterprises to participate in personnel training, curriculum development, training base construction and other aspects, the logistics personnel training to achieve "enterprise plant" and the effective integration of 
government, industry, business and other aspects of resources. In recent years, vocational college logistics professionals have a greater development in school-enterprise cooperation, but look at the quality of school-enterprise cooperation and to be further strengthened. The quality of school-enterprise cooperation directly affects the quality of Higher Education Logistics. Explore the school-enterprise cooperation both collaborative innovation system and mechanism, industrial transformation and upgrading service features professional construction logistics, the whole "dual" training program training, industries and enterprises in personnel training and evaluation criteria and other mechanisms will be high logistics professional vocational schools school-enterprise cooperation, specialty, specialty construction, personnel training and collaborative innovation provides valuable theoretical and practical reference for the professional running quality and enhance the level of higher vocational college, logistics make a great contribution.

\section{School-enterprise Cooperation Logistics Problems}

At the national level, although school-enterprise cooperation is encouraged, but in practice, the prevalence of co-operation between schools and enterprises is not standardized, the direction is unknown, co-foundation is weak, the lack of policy support and other issues. These problems attributed to two aspects: first, countries do not have the perfect incentive to participate in school-enterprise cooperation enterprise incentive measures to ensure the company's own interests; the second is the lack of national school-enterprise cooperation on the establishment of the Governing Body clearly defined, resulting in a lack of management throughout the school-enterprise cooperation in curriculum design and operation of professional supervision and performance appraisal, seriously affect the further development of cooperation between schools and enterprises. Besides the lack of schools, local governments do not have the characteristics and trends in the region's economic development, the lack of focus on the development and trends in public local logistics industry in the region and which need to have the ability to logistics personnel as well as personnel training and professional orientation, etc. guide enterprise cooperation.

Logistics enterprises to participate in school-enterprise cooperation enthusiasm is not high, mainly due to its own economic interests are not guaranteed or suffer. On the corporate side, a logistics class jobs require experienced staff to bear, put some idle job to train college students do not have practical experience is bound to affect job performance. Moreover, the local government has no business to make up for the economic interests of the corresponding tax incentives. In addition, the companies hope to learn more cooperation in the logistics industry expertise and some of the advanced concepts, but the result is not good business to get them. This lack of business interests led to College cold hot business situation occurred in school-enterprise cooperation, is not conducive to long-term development of school-enterprise cooperation.

The main problem faced by school-enterprise cooperation in common is the lack of logistics practice of experienced teachers colleges and universities, is not conducive to the cultivation of theoretical knowledge and practical experience of both logistics personnel. Currently, logistics management professional teachers are mostly from the business management of transport engineering economics and other disciplines turn over, little practical experience in logistics management, lack of capacity to guide practice. To solve this problem, in addition to hands-on aspect of Teachers Training Colleges and Universities, more importantly, the government needs to introduce teachers to experience business practices and provide policy support and protection, and the organization of logistics experts to practice the university teachers unified training, ensure the training of high quality and efficiency. At the same time, school-enterprise cooperation to improve the quality of teaching materials, teaching order stability plays a very important role, but less suitable for teaching authority. Since the school-enterprise cooperation to develop materials to be closely integrated with curriculum development, and joint development of industries and enterprises in close connection with the actual production of materials should be based on the technical field and professional positions (group) of the requirements, refer to the relevant professional qualification standards, reform the curriculum system and teaching content, inviting the industry to explore business people together, listen to the views of industry, business management and technical 
staff, the production line with the industry's actual content textbooks written. Thus, school-enterprise cooperation textbook is a systematic project, which requires brainstorming. Did not participate in the government, universities and companies alone is difficult to develop a suitable high-quality materials.

\section{Logistics Management Talents Training Mode of School-Enterprise Cooperation Innovation}

Construction of combined training model reform and training base, to further the implementation of combining learning with internships and other training model of reform, the implementation of on-site work experience Teaching Approach Teaching and Practical Training Project Approach For operability strong professional core courses, such as warehousing and distribution management practices (logistics IT practices (like focus on training application skills, practical content into a comprehensive training base in schools or joint venture production site to implement. cultivating talents as the goal of zero adapt to school College of business people to build a modern logistics platform, adhere to the concept of industry-oriented personnel training services industry, the scientific prediction and adaptation to the development needs of the logistics industry, the logistics industry to conduct special research and analysis and demonstration, the use of their own resources and mining Institute, dynamic adjustment of the professional personnel training programs, and actively explore and practice of engineering alternately internship and other training model to achieve class and job students and apprentices teachers and teacher classroom and workshop teaching aids and tools of organic unity. Training professional core competencies warehousing and supply chain management have transportation and distribution, proficiency in the use of modern information technology, familiar with modern logistics-related technologies and processes, and business management to understand management, companies need to adapt to industry for high-quality high-skilled talents.

Logistics Management division of roles according to industry guide enterprises to participate in College subject, deepen the connotation of school-enterprise cooperation and innovation embedded engineering industry orders, three alternating training model, training to master the actual operational processes proficient professional skills to adapt to the social needs of high skilled talents.

Based on demand-oriented industries Order Training Mode Each of logistics enterprises in Suzhou according to the business people demand and human resource development programs to Suzhou Logistics Chamber of Commerce logistics personnel requirements planning and information, logistics Chamber of Commerce integration categories logistics personnel needs, to modern logistics Institute issued talent demand orders, the school-enterprise cooperation steering committee under the aegis of the line school level tripartite complete the design and development of personnel training program by the modern logistics institute culture according to school-enterprise co-educating people organizing principle embodiment Order talent Training after students complete their studies, the Suzhou logistics Association according to business needs and market conditions, reasonable arrangements for students to swap jobs.

Based on total fertility-linked training embedded training mode. College and modern logistics joint venture with mutual benefit, based on demand from the logistics management positions with reference to standard industry enterprise, full participation in the process of personnel training, professional standards jointly developed post embedded business courses in personnel training programs, the introduction of business people in the teaching process, sharing enterprise work site in training students through a full range of content embedded embedded embedded resource teacher, to maximize the sharing of resources between schools and enterprises of the United training achieve professional personnel training.

Based on the elastic-semester engineering alternating training mode. Modern Logistics Institute will adopt a multi semester segmented spring semester in the form of innovative engineering alternating training model. The so-called elastic term refers to the nature of the term length and term is elastic, will the length of the term with the major binding skills project, short or long; the term designated as business school semester and the semester so that not only meet the engineering 
requirements of alternating training mode, but also fit the teaching cycle and the production cycle and differentiating teaching content. Requirements difference, to achieve effective classroom and job docking, master teachers and classroom teaching aids and tools and workshop organic unity, to achieve zero adaptation of training objectives.

\section{Conclusion}

In general, vocational colleges and enterprises in the school-enterprise cooperation in the partnership should be equal, mutually beneficial cooperation is under the safeguards system of the government's conduct, without government guidance and support. If government policy is stable, so that schools and businesses would stand in the perspective of long-term development, to enhance cooperation between the two sides, the two sides in order to avoid the possibility of reducing the risk and to make other choices, so that both schools and enterprises in order to truly mutual trust as a basis for cooperation. In addition, the government also needs to assume the responsibility to make up for losses that may occur, such as through effective economic lever to the enterprise a certain behavior incentive for companies to participate in cooperative education appropriate to give some tax breaks or subsidies.

\section{Acknowledgements}

Fund Project: 2015, Humanities and Social Sciences in University in Jiangxi task Youth Project (JY1572);

2015 Nanchang Institute of Humanities and Social Sciences issue general project (GJRW15-09).

\section{References}

[1] RUSTUM R. University-industry interaction patterns [J]. Science, New Series, 1972,178 (4064): 955-960.

[2] Geisker, E, and Rubenstein, A (1989), University-Industry Relations: A Review of Major Issues, Albert Link \& Gregory Tassey (eds), Cooperative Research \& Development, Kluwa Academic Publishers.

[3] Senker. A. Rationale for Partnerships: building national innovation systems. Snreview [J]. 1998 (23): 23-37.

[4] Van Huyck, J, R.C. Battalio and R. O. Beil. Tacit Coordination Games, Strategic Uncertainty and Coordination Failure [J]. American Economic Re-view, 1990 (80). 